\title{
Teatro como acontecimento convival: uma entrevista com Jorge Dubatti ${ }^{1}$
}

Theater as event: an interview with Jorge Dubatti

Entrevista concedida à Luciana Eastwood

Romagnolli2 e Mariana de Lima Muniz ${ }^{3}$

Em fev. 2014, nas dependências Centro Cultural de la Cooperación, Buenos Aires, Argentina 
Jorge Dubatti em seu empenho por traçar uma filosofia do teatro, o ensaísta,o crítico e teórico argentino Jorge Dubatti reconhece que, assim como a Arte em geral, o teatro passa por um processo de "desdefinição" com a emergência de acontecimentos artísticos fronteiriços desde o início do século XX; contudo, apesar dessa desdelimitação com outras artes e com a vida, Dubatti identifica ainda "uma singularidade na teatralidade que é sua estrutura matriz" (2007, p. 14) e que o diferencia de outras manifestações culturais também fundadas na representação, como o cinema, a televisão e o jornalismo. Essa singularidade é "o resgate do convívio", ou seja, "a reunião sem intermediação tecnológica - o encontro de pessoa a pessoa em escala humana" (Dubatti, 2007, p. 20) em uma "encruzilhada espaço-temporal cotidiana" (2007, p. 43).

Dubatti propõe, então, uma definição ontológica da composição interna do teatro. Segundo ele, o teatro é conformado pela tríade acontecimento convival, acontecimento poiético e expectação, necessariamente associados. Portanto, o convívio deve estar associado à poiésis, que é o material artístico e sua criação, portanto, necessariamente poiético, ainda que possa ou não ser ficcional, trata-se de um duplo frente à realidade e não necessariamente sua negação. Nas palavras de Dubatti, a "produção de um ente poético, dotado de traços ontológicos singulares, a partir do qual se produzem processos de semiotização que nunca se completam ou se esgotam" (2007, p. 89). E a essas duas dimensões se soma a expectação: o campo de constituição do espaço de percepção do espectador, onde o teatro enfim se constitui como tal, mas não sem os outros dois fatores anteriores. Em síntese, o teatro "é a produção e expectação de acontecimentos poiéticos corporais em convívio" (Dubatti, 2007, p. 36).

$\mathrm{Na}$ entrevista abaixo, realizada em fevereiro de 2014, no Centro Cultural de la Cooperación, localizado no centro da cidade de Buenos Aires, o teórico argentino relaciona sua ontologia teatral às possibilidades de dramaturgias conviviais, à crítica de teatro e à necessidade de uma mudança de paradigma na pesquisa sobre teatro cartografada que o entenda não como linguagem tão-somente, mas também como acontecimento.

ISSN: 1414.5731

E-ISSN: 2358.6958

1 Jorge Dubatti (Buenos Aires, 1963), Prof. Dr. Universidade de Buenos Aires, onde atua em História e Teoria Teatral, bem como na Universidade Nacional de Rosário e Universidade Nacional de San Martín, Argentina.
2 Mestre em Artes (UFMG). Jornalista e crítica de teatro. lucianaromagnolli@gmail.com

3 Profa. Dra. Programa de Pós-graduação da Escola de Belas Artes, Universidade Federal de Minas Gerais (UFMG). Atriz e diretora teatral. 
Luciana e Mariana - Se pensarmos a dramaturgia fora do logocentrismo como um conceito expandido que inclui a articulação de sentidos e efeitos num espetáculo, é possível pensar o convívio como elemento que pode ser trabalhado pelo dramaturgo e pelo diretor, de modo que se possa evidenciar a relação de convívio no espetáculo?

Jorge Dubatti - Como você disse, o conceito de dramaturgia se ampliou enormemente, do ponto de vista do sujeito produtor, do sistema de referência, da edição etc. Acaba de sair no Chile um trabalho meu sobre esse tema. Dentro dessa ampliação, entraria o que podemos chamar de dramaturgias conviviais. São aquelas dramaturgias que, seja pela liberdade que tem o ator para interagir com os espectadores ou pela imposição do convívio sobre o material da cena, produziriam um caso particular. Digamos que o ator deixa de ser uma simples tecnologia do diretor para transformar-se em um gerador de acontecimento convivial, que implica produção de dramaturgia. Nesse sentido, creio que a dramaturgia convivial é vivida todo o tempo, inclusive nos espetáculos em que o ator está determinado a cumprir com um determinado protocolo de representação do texto ou a cumprir com as instruções de um diretor, porque o convívio produz modificações. Se alguém medir a duração de uma obra em cada sessão, verá que nunca é a mesma. Por outro lado, há mudanças na ordem dramatúrgica não só pela dinâmica de convívio, mas também pela dinâmica de produção de poiésis - a poiésis produtiva, segundo a terminologia da Filosofia do Teatro. Nesse sentido, há de se distinguir dois tipos de dramaturgias conviviais. Um tipo seria aquela que é natural do acontecimento convivial e vai acontecer sempre, mesmo que o ator trabalhe com quarta parede e se isole do mundo, essa dramaturgia vai estar em funcionamento. Outro tipo são casos muito particulares de distintas poéticas que trabalham com o que podemos chamar de uma "dramaturgia do ator em convívio", no qual o ator interage permanentemente ou aproveita os estímulos. É como na Commedia dell'Arte ou no teatro de rua ou em algumas poéticas particulares. Na Argentina, temos a poética do clown, da improvisação e da comicidade, que são muito abertas à dramaturgia da produção de convívio a cada noite. Há vários grupos que têm essa poética instaurada. Um caso que eu nomearia como exemplar é do La Banda de la Risa, que trabalha com uma margem muito forte de dramaturgia convivial, modificando permanentemente as apresentações com estratégias que são muito parecidas com as da Commedia dell'Arte, como o canovaccio e a construção de lugares inesperados dentro dessa dramaturgia.

Luciana e Mariana - O segundo tipo de dramaturgia convivial, você relaciona ao ator. Com outros elementos, como luz e cenário, também seria possível criar esse tipo de poética da dramaturgia convivial?

Jorge Dubatti - Sim. O que creio é que o específico do teatro, seu núcleo central, é o ator. Há cenas neotecnológicas em que se produzem combinatórias, mas o que não se pode subtrair é o ator. Ele verdadeiramente é o gerador da ação, da poética e do acontecimento. Isso seria a refutação da teoria de Josette Féral. Féral diz 
que a dramaturgia é o olhar do espectador. Então eu poderia, neste momento, estar olhando para você e pensando nesta entrevista como uma obra de teatro. Não. A poiésis teatral diz que se trata de uma ética dialógica, uma política dialógica. Quando alguém vai ao teatro, vai compartilhar com outro. Não está fechado em seu próprio crânio. Uma ética dialógica seria entrarmos em acordo de que eles (os atores) vão produzir poiésis e nós vamos observar e nos integrar numa poiésis convivial. Essa é a grande diferença entre uma definição geral de poiésis e uma definição específica do teatral. Caso contrário, o teatro perde sua singularidade. É claro que existem zonas de liminaridades, cruzamento e perda de limites. Mas a singularidade (do teatro) é haver uma "figura de ação" que comece a produzir poiésis e, a partir daí, detonar todo o mecanismo. Essa figura é o ator.

Luciana e Mariana - Faz sentido dizer que, quando o teatro evidencia a poiésis convivial, reitera sua importância na atualidade?

Jorge Dubatti - Absolutamente. É claro que há uma grande variedade de poéticas e, dentro de uma ética do científico (estou trabalhando muito esse tema), tenho que valorar e respeitar todas as poéticas.

Luciana e Mariana - Ou seja, ser um espectador "politeísta", como você diz em "Filosofia do Teatro I".

Jorge Dubatti - Exatamente. Chamo de cânone da multiplicidade. Um artista pode dizer o contrário: só é arte o que eu faço. Mas um cientista não pode fazer isso. Se sou investigador, tenho que reconhecer tudo que está acontecendo e aceitar que há muitas formas de fazer teatro. Mas há algo interessante que é um núcleo de teatro, com estabilidade, que provém da Antiguidade e segue vigente. $O$ acontecimento é efêmero, mas a memória não. Há uma memória do teatro que segue funcionando e teria a ver com esse núcleo central. O núcleo fundamental, como disse Grotowski e também Peter Brook, estaria dado no sistema de convenção do século V a.C, com a tragédia e a comédia gregas e os mimos romanos. Nesse sentido, gosto muito de usar a palavra teatro. Muitos perguntam por que não falar em "artes cênicas". O problema com as artes cênicas é que todo mundo se apropriou da palavra cena: a sociologia, a literatura, as artes digitais. Eu teria que separar artes cênicas conviviais e não conviviais. A palavra teatro, usada no sentido de origem, não o moderno, implica todos os elementos dessa estabilização da linguagem teatral que continua vigente até hoje. Teatro significa lugar, um mirante, onde alguém vai ver algo que aparece. Por outro lado, há a atividade de olhar. Portanto, na palavra teatro estão inscritos o território, o objeto observado e o observador. Voltando ao núcleo, as combinatórias são infinitas, especialmente depois do choque das vanguardas, muito estimulante para se ler a História [do teatro]. Por que não sustentamos que o primeiro ator foi Homero? Ali havia convívio, poiésis e expectação. Se fizermos todo esse protocolo de regresso à História e voltarmos a pensar nos processos, além da multiplicidade aparece um elemento irrenunciável, que é o ator. Há um grande dramaturgo argentino, Mauricio Kartun, que diz: o teatro é um corpo. O que está dizendo é: o teatro é um corpo de 
um ator que produz acontecimento e estabelece uma ética dialógica com o espectador. Nesse sentido, creio que as luzes, a cenografia, a música, são todos elementos muito importantes, mas são acessórios porque, como diz Grotowski, poderíamos tirá-los e o acontecimento se produziria. Então, eu instalaria dois corredores teóricos. Um seria de quantas possíveis combinatórias há dentro das linguagens teatrais: infinitas. E outro corredor teórico seria o que não pode faltar no acontecimento teatral: a reunião dos corpos viventes produzindo poiésis em convívio, onde haja geração corporal de poiésis e expectação. Seriam duas pertinências diferentes, como dizem os estruturalistas. Por isso, no fundo, a dramaturgia convivial é constitutiva do teatro. Em alguns casos pode ser sistêmica, porque se busca estimular esse convívio, em outros casos não, mas ainda assim está presente.

Luciana e Mariana - Falta se pensar mais sobre o espectador e a experiência de expectação na teoria de teatro?

Jorge Dubatti - Você está tocando em um tema que, para mim, é um tema-chave. Nós temos armado uma epistemologia do teatro baseada na ideia do teatro como linguagem. Uma ideia da linguagem como um corpo que produz signos e que são expectados por outro corpo que produz sentidos através desses signos. Toda a teoria básica é a da comunicação. Mas há outra coisa que é importante e é justamente a convivialidade. O grande problema em que nos encontramos é que há de se armar uma epistemologia da convivialidade, não da linguagem, porque a linguagem não necessariamente é o que ocorre no acontecimento. Se estou observando um corpo que produz acontecimento, de golpe me abstraio porque o relaciono com alguma coisa e deixo de perceber os signos. Onde fica a teoria de que houve comunicação ou que esse signo produziu recepção em mim? Nesse sentido, temos que reinstalar um campo epistemológico, que muitas vezes foi tapado pela vontade de certeza da semiótica. Por exemplo, leio um texto, analiso os signos desse texto e os projetos ao funcionamento do espetáculo, pensando que foi isso que se passou. A epistemologia do convivial implicaria ver como fracassa a linguagem. Beckett disse: tenta de novo, fracassa de novo, fracassa melhor. Tenho que ver onde fracassa a teoria semiótica porque é aí que estou entendendo a singularidade do teatro.

\section{Luciana e Mariana - O que não é texto, mas é acontecimento.}

Jorge Dubatti - Sim. Tenho que poder pensar o acontecimento pelo que ele é, não pelo que deveria ser enquanto linguagem semiótica. Não digo que não há linguagem, mas que, no acontecimento, há muito mais que linguagem. $\mathrm{E}$ o acontecimento, como pertence à cultura vivente, implica categorias epistemológicas muito importantes, como a categoria do perdido, da ignorância - porque há coisas que vou ignorar. Trabalho com espectadores todas as segundas, na Escola de Espectadores, de março a novembro, e estou disposto a não saber o que se passou porque o acontecimento é muito mais intenso do que os relatos posteriores ou uma estatística. Uma coisa que me parece muito importante - e estamos tratando de aprofundá-la é aceitar que o acontecimento teatral nos enfrenta com um limite. E que esse limite 
não se pode negar nem se pode tapar. O que a semiótica fez foi negar e tapar os limites, pensando que se estudamos as cadeias de signos, estudamos o acontecimento. Estamos nas portas de uma nova maneira de entender as coisas, onde nos colocamos num lugar de reconhecimento e de fracasso.

\section{Luciana e Mariana - Essa é uma tarefa para o pesquisador e uma tarefa para o crítico?}

Jorge Dubatti - Totalmente.

\section{Luciana e Mariana - Como fazer isso? Como falar do acontecimento?}

Jorge Dubatti - Uma coisa importantíssima é começar a ter categorias que reconheçam a realidade do acontecimento, como a categoria do "teatro perdido". Quando vou falar do teatro como crítico, eu falo no passado, não no presente. Estamos falando do perdido, mesmo que o tenhamos visto há dez minutos. Isso implica em primeiro lugar que, a partir dessas categorizações, formulemos do que podemos falar e do que não podemos falar. Quando reconhecemos aquilo do que podemos falar, aparece um monte de questões que se instalam em certos parâmetros. Eu tenho, como crítico, dez grandes parâmetros que têm a ver com um trabalho sobre auto-observação e observação do acontecimento. Trabalho muito com a ideia de auto-observação, o relato do que passou comigo. O acontecimento em princípio é um laboratório de auto-observação tanto para o artista quanto para o espectador e para os técnicos. Há de se habilitar o lugar do técnico. Na Argentina, agora chamamse técnicos-artistas, porque se reconhece que estão fazendo algo muito importante para a poiésis. A técnica é tão protagonista quanto o trabalho do ator e do espectador. Então, auto-observação e construção de discursos sobre essa auto-observação, tanto pelo espectador, quanto pelo técnico e pelo artista. Começam a aparecer categorias, observações históricas, regularidades, reflexões de todo o tipo sobre as conexões com a história e o comportamento. Mas tudo isso baseado no reconhecimento de uma ignorância. A ignorância qual seria? O objeto se perde. Estudar um vídeo não é estudar um acontecimento. Tem-se que estar dentro do acontecimento. E outro tema muito importante é a excepcionalidade do acontecimento. Posso entrar no teatro drogado, feliz no meu mundo, e o espetáculo me parecer maravilhoso porque estou disposto a que seja maravilhoso. Ou o contrário: entro após uma má notícia, de que estou doente, não sei, estou desesperado e odeio o espetáculo porque o relaciono a isso. São muito importantes as categorias da auto-observação, da autodisciplina, da autoconfiança. E algo tão importante quanto é alcançar um lugar trans-subjetivação como espectador, não apenas o subjetivo. Está muito relacionado à ideia da morte: se eu não estivesse hoje aqui, a apresentação igualmente estaria acontecendo. Posso abstrair a minha própria presença e pôr em jogo a observação, não como um sujeito afetado por ela, mas como algo que está acontecendo na minha ausência. Isso implica um exercício epistemológico. No teatro nem tudo é subjetivo. Se estou sentado e a meu lado uma senhora está morrendo de rir, posso observar isso como uma instância objetiva do acontecimento. Simultaneamente, na ordem 
subjetiva, posso dizer que não me interessa, me incomoda, posso valorar o que está acontecendo. São muitas estratégias distintas - passei o verão escrevendo sobre isso. Outra estratégia é uma espécie de diálogo com pessoas ausentes no acontecimento. Sabe quando Eugênio Barba diz que pensa o espetáculo para seis espectadores uma criança, Borges, um músico, um cego etc.? Essas pessoas não vão ao acontecimento, mas Barba o está construindo a partir de um lugar de pergunta, tirando-o da instância estritamente subjetiva dele. Eu sempre fantasio que vou ao teatro com dois amigos - que obviamente não vão -, o Martin Esslin, crítico criador do conceito de teatro do absurdo, e Susan Sontag, a intelectual americana. Sempre me pergunto o que estariam vendo eles que eu não estou vendo. Trata-se de pensar não só o que estou vendo, mas o que poderia estar vendo e o que deveria estar vendo. Então, abre-se um monte de possibilidades à pergunta sobre os convívios, relacionadas à auto-observação, à observação do outro e a instâncias imaginárias que permitam fazer ao acontecimento perguntas que não se faria por sua própria subjetividade.

Luciana e Mariana - Se pensarmos na processualização de espetáculos, característica do pensamento de vanguarda nas artes, pela qual se traz elementos do processo criativo para a obra, há uma relação entre essa prática e o convívio?

Jorge Dubatti - A grande pergunta que se deve fazer é o que eu posso conhecer de um convívio. O convívio é um objeto de estudo evanescente, absolutamente imprevisível. Muitas vezes é difícil predicar algo sobre esse objeto. Então aparece uma pergunta epistemológica interessante: quais são os limites de conhecimento do convívio enquanto objeto? Dentro dessa grande pergunta há uma em particular que seriam os estudos dos processos de convívio. Podemos dizer que cada convívio é absolutamente diferente de outro. Posso encontrar regras de regularidade, mas talvez o mais interessante não seja a regularidade, mas aquilo que o convívio muda. Espetáculos que me interessam muito, vejo-os mais de uma vez. É impressionante não só como eu mudo na relação com o acontecimento já tendo visto o espetáculo uma vez, mas também como muda o acontecimento pela nova composição do público e pelo estado dos atores. Isso já foi muito dito: a apresentação nunca é a mesma. Mas há de se produzir categorias. Temos que partir da ideia de que estudar os convívios implica estudá-los micropoéticamente. Não vou estudar todos os convívios porque não poderei estar lá. Se, dentro de todos esses convívios, seleciono um, aí estarei estudando uma micropoética em particular. Questiono muito as observações dos críticos - e me incluo - valorando um espetáculo pelo que se passou numa apresentação com outros críticos [na plateia]. Há que se poder nomear certos critérios. Tenho pelo menos dez grandes critérios: efetividade, historicidade, poeticidade etc. Mas o mais importante é o micropoético: reconhecer cada convívio e cada acontecimento como único e singular e não necessariamente representativo dos outros. Há algo que contradiz a investigação: tratamos de generalizar algo que não se pode generalizar. A relação está dada por uma circunstância, um momento, uma tensão de relações absolutamente micro, não esse modelo abstrato. Por isso sempre que estudamos o convívio peço aos espectadores que digam que dia foi, em qual apresentação, se esteve presente ou não, sobre qual vídeo está trabalhando e que esclareça que está 
trabalhando sobre um vídeo porque é uma observação extremamente relativa. Sinto que, de tudo que se escreveu sobre teatro, trabalhou-se sobre generalidades, sobre sistemas. E a sensação é que nos acontecimentos essas generalidades não necessariamente estão presentes. Por exemplo, fui a uma apresentação em que espectadores aplaudiram de pé e depois ouvi de outra em que os espectadores dormiram, saíram na metade. Estamos falando do mesmo objeto? São dois objetos diferentes: um convívio e outro convívio.

Luciana e Mariana - Na Escola de Espectadores, são quantos anos de trabalho?

Jorge Dubatti - Quatorze anos.

Luciana e Mariana - E, nesses anos, o que você pôde sentir de como os encontros semanais podem mudar a relação desses espectadores com o teatro e a sua com esses espectadores?

Jorge Dubatti - É um fenômeno muito complexo. Comecei com oito pessoas na escola e há seis que continuam vindo em 14 anos. Neste momento, a escola tem 340 frequentadores. Encontram-se pessoas com respostas muito distintas, histórias diferentes de relação com teatro. Gente que vem com estrutura muito armada, vai ver teatro comercial e nega, vai ver teatro independente e mesmo que seja uma porcaria encanta-se. São cabeças muito diferentes, 340 tipos distintos. Mas o que eu vejo como função da escola é que possa construir o que gosto de chamar de espectador companheiro. É um ponto contrário ao espectador emancipado de (Jacques) Rancière. O espectador companheiro está disposto a dialogar com o que acontece, tomando a instância objetiva do espetáculo, de reconhecimento do que está acontecendo ao redor, e estabelecendo um diálogo entre o que se passa com ele, com os outros e com o artista, nessa instância trans-subjetivada de colocar-se em outro lugar. A escola multiplica a vontade de escuta, de atenção a outras pessoas do convívio e aos artistas. A escola gera conhecimento, o frequentador que vem há dois ou três anos está muito preparado para ler linguagens diferentes. Gera uma mudança muito forte no boca a boca. Se gostam do espetáculo, os 340 se multiplicam por dez rapidamente, há uma rede de oralidade. Gera um movimento de público para o espetáculo.

\section{Luciana e Mariana - Como você desenvolve a pedagogia teatral na Escola?}

Jorge Dubatti - O que eu sempre digo: é uma escola, não é um clube. Não é um lugar de debate aonde cada qual vem dizer o que lhe ocorre. Há uma franja educativa. Eu dou aulas com um critério construtivista, não condutivo. Não lhes digo o que têm que pensar ou fazer. Eu lhes dou ferramentas. Por exemplo, suponhamos que vejamos um "Hamlet" dirigido por Daniel Veronese. Na primeira hora da Escola, vou dar ferramentas para compreender o texto de Hamlet, compreender a tradução sobre a qual se está trabalhando, ver uma tecnologia da reescritura (o que chamaríamos adaptação), conectar com o pensamento e a poética de Veronese e do que 
seria um Shakespeare em sua historicidade. Em nenhum momento digo se devem ou não gostar. Eles brigam muito comigo. Digo para verem algo e voltam dizendo que é uma porcaria. Peço que se deem tempo. Já aconteceu de me dizerem que um espetáculo é um desastre e, sete anos depois, o mesmo espectador me dizer que agora entende porque foi ver tal coisa. Isso é uma aprendizagem e uma abertura que tem muito a ver com a vontade de abrir a cabeça. Gosto muito de falar em amigabilidade, disponibilidade espiritual com os acontecimentos. Na segunda hora, vêm os artistas, o diretor, o dramaturgo, o produtor, os técnicos, e o que fazemos é escutá-los muito atentamente. Não dizer-lhes o que nós pensamos mas escutar o que eles pensam. $\mathrm{E}$ fundamentalmente as perguntas são: como trabalharam, como veem o mundo, por que fizeram isso, quais os principais procedimentos e perguntar muitos detalhes. "Na cena do monólogo tal, você faz de costas. Por quê?". Sempre aparece a ideia do diálogo com o artista. Uma ideia de companheiro - que vem do latim, compartilhar o pão. O convívio é justamente a mesa, uma reunião para beber e comer. Tenho uma espécie de classificação dos contramodelos de espectador, os que eu não recomendo, e dentro deles está justamente o não-companheiro, o espectador assessor, credor, carrasco. São distintos tipos de espectadores que reconheci e, quando aparecem, trato de lhes trazer consciência. Já se passaram na Escola casos incríveis, como trazer um mestre de trajetória impressionante, que se digna a vir conversar conosco, e nem começou a falar quando uma senhora levantou a mão e disse que o espetáculo não lhe interessou porque é uma merda. Isso seria o espectador carrasco, combativo, que não vai disposto ao diálogo, mas para violentar. Isso é muito midiático, está na televisão, muita gente pensa que isso é o protagonismo. Alguns espectadores da Escola me disseram que vão lá questionar e criticar os artistas. Não se trata disso, se quiserem, que abram um blog e escrevam o que queiram. A Escola é um espaço de diálogo em termos de companheirismo. Às vezes, isso me custa muito. As pessoas têm uma tendência à violência e não sabem dialogar, mas quando isso acontece, eu o freio, porque não é a função da Escola. Não é ensinar o que se tem que pensar ou as conclusões, mas exige da pessoa a disponibilidade de receber ferramentas. Uma dessas ferramentas é tratar de entender a cabeça do artista, o que ele quis e propôs. Depois, considere se conseguiu ou não.

Luciana e Mariana - No Brasil, há uma escola em Porto Alegre. É possível se pensar em escolas em outras cidades?

Jorge Dubatti - Um grupo me chamou para abrir em São Paulo. Creio que sim. Vivendo em Buenos Aires, que é uma grande capital teatral, comecei com oito pessoas e com muita resistência. Ninguém entendia que teria que estudar para ser espectador - eu dizia, claro que tem de estudar, eu vivo estudando para ser um bom espectador. Não entendiam do que teriam aulas. Sinto que isso já se instalou aqui. No Brasil, a Escola de Porto Alegre começou com 150 pessoas. Já está criada a expectativa. Fez-se uma reunião no Festival Santiago a Mil e se falou da Escola de Espectadores de Buenos Aires. Mas creio que em São Paulo já há um rapaz, o Flávio Desgranges, que está fazendo escola de espectadores, mas nas escolas de educação básica. São duas coisas distintas. Não trabalho com escolas, trabalho com espectadores. Estamos 
armando um módulo para trabalhar com as escolas, mas sou muito crítico da forma que se está trabalhando neste momento porque não creio que se deva transformar o espetáculo e o acontecimento em um espaço pedagógico. Tem que ser puro espaço de gozo. Levar as crianças para que se divertir, desfrutar, como uma excursão. E que não se transforme em uma aula, como de literatura.

\section{Luciana e Mariana - Seu livro será publicado no Brasil?}

Jorge Dubatti - Aparentemente, sairia uma introdução à Filosofia do Teatro, publicada em São Paulo pelo Sesc. Estou terminando a versão e vou mandá-la, terá de ser revisada, aprovada, traduzida. Tomara! Me encantaria porque estou viajando muito ao Brasil, tenho conexões com universidades de distintos lugares e vejo que estamos na mesma coordenada. Estamos em uma etapa de abertura epistemológica a uma consideração do teatro a partir de um outro lugar. Gosto muito do pensamento cartografado. Não se trata de impor um novo paradigma universal, como a semiótica pretendeu ser. O que se trata é de, problematizando as questões, estudar os contextos locais. Eu estudo Buenos Aires e a partir daqui produzo um pensamento teórico. Me parece que o mesmo têm de fazer Brasil, Uruguai, Córdoba. E isso está acontecendo. É uma ideia de uma cartografia radicante. No Rio se estuda uma coisa, em Buenos Aires outra, em Córdoba outra, em estreita relação com o teatro que vemos. Senão, gera-se essa coisa espantosa é termos de falar sobre o que está se passando na Alemanha, quando não é o teatro que vemos. Isso nos obriga a não termos objeto de estudo, a repetir a bibliografia e a desconhecer nosso próprio objeto de estudo. Uma cartografia radicante diria: tenho que pensar o teatro a partir do que eu sei. Tive uma entrevista com um grande pesquisador francês que levei à Universidade de Buenos Aires, e ele disse aos alunos: "Porque vocês viram Planchont...". Não. Ninguém viu. Ele me olhou: "não conhecem Planchont?" Chegou um momento em que me disse que não poderia prosseguir. Eu the disse para falar de teatro, não das obras que ele viu, porque eles falariam das obras que eles viram. Uma cartografia radicante implica conhecer a própria territorialidade e estabelecer diálogos de conexão com França, Alemanha, com todo lado, mas a partir do que se conhece, dos acontecimentos. Não tenho porque estar falando de Bob Wilson, vou falar do que vejo esta noite e daí vou produzir pensamento e me conectar com toda a bibliografia mundial. Essa é uma mudança muito importante porque começamos a reconhecer que temos que falar do que se passa e não do que deveria estar passando. Falei disso com o Lehmann em Porto Alegre, num encontro sobre Bertolt Brecht, conversamos nos almoços, caminhando pela rua. Disse-lhe: "o conceito que você trabalha de pós-dramaticidade não me serve para pensar o teatro de Buenos Aires, o teatro que eu vejo não é o que você diz". E ele me respondeu uma coisa muito sensata: "Eu nunca falei do teatro de vocês, estou falando do que eu vejo lá". Isso me parece muito importante, devemos começar a falar de coisas concretas, e claro, depois ouvir atentamente ao Lehmann para ver se o que ele diz tem a ver com o que vivemos. Nos congressos, muitas vezes, sinto que estamos vendo uma coisa e falamos de outra. Acabamos de ver uma obra de teatro em que há personagem, história, dramaticidade e, depois, analisamos esse espetáculo falando de pós-dramaticidade e morte do personagem. Não tem nada a 
ver com o que vemos. A América Latina tem uma missão agora: começar a falar do que se passa nos teatros locais. Tenho que falar de Buenos Aires. E você tem que falar do teatro do seu lugar. E, claro, conhecer toda a bibliografia mundial.

\section{Referência}

DUBATTI, Jorge. Filosofia del Teatro l: convivio, experiencia, subjetividade. Buenos Aires: Atuel, 2007.

Recebido em: 26/06/2014 Aprovado em: 08/09/2014 